\title{
Living the Present with an Enemy from the Past: The Role of Noninvasive Ventilation in a Poliomyelitis Survivor
}

\author{
Adelaide Alves*, Sara Conde and Carla Ribeiro
}

Pulmonology Department of Centro Hospitalar de Vila Nova de Gaia/Espinho, Portugal

*Corresponding author: Alves A, Pulmonology Department of Centro Hospitalar de Vila Nova de Gaia/Espinho, Portugal, Rua Conceição Fernandes, 4434-502 Vila Nova de Gaia, Portugal, Tel: +351 910237 111; E-mail: adelaide.pereira.alves@gmail.com

Received: April 15, 2021; Accepted: April 22, 2021; Published: April 30, 2021

\begin{abstract}
Poliomyelitis epidemics of the twentieth century boosted the development of noninvasive positive-pressure ventilation which has changed the natural history and extended survival in a wide range of disorders with chest wall and muscular involvement. Poliomyelitis has almost been eradicated from developed countries since the introduction of vaccination. However, challenges keep coming since there are a substantial number of survivors of the disease who need particular clinical care, namely in the respiratory field. We present a case report of a polio survivor attempting to demonstrate that even after so many years the respiratory approach of these patients remains a current issue in clinical practice with noninvasive ventilation as a cornerstone element.
\end{abstract}

Keywords: Poliomyelitis; Respiratory failure; Noninvasive ventilation

\section{Introduction}

Poliomyelitis is a highly infectious disease caused by poliovirus, primarily affecting children under five years of age [1]. In rare cases $(<1 \%)$, viral strains target the motor neurons in the spinal anterior horn and the brain stem, resulting in muscle weakness and flaccid paralysis (known as paralytic poliomyelitis or polio) [2]. Mortality is related to respiratory failure which may be caused firstly by diaphragm paralysis and intercostal muscles and secondly by obstruction of the airway as a consequence of paralysis of the muscles related to swallowing, which is the most important feature of bulbar involvement [3]. In mid-20 $0^{\text {th }}$ century, Copenhagen was struck by a severe epidemic of poliomyelitis including a large number of cases of bulbar polio resulting in respiratory paralysis and acute respiratory failure [4]. Noninvasive negative-pressure ventilation by iron lung saved thousands of lives [5]. However, iron lungs were cumbersome, expensive and upper airway obstruction provoked by the

Citation: Alves A, Conde S, Ribeiro C. Living the Present with an Enemy from the Past: The Role of Noninvasive Ventilation in a Poliomyelitis Survivor. Clin Case Rep Open Access. 2021;4(2):185. 
negative pressure was a common problem. The increasing number of deaths from bulbar poliomyelitis demanded a new therapeutic approach leading to the emergence of modern positive-pressure ventilation [4,5]. Since then, improvements in ventilator technology and mask design led to widespread use of noninvasive ventilation in several indications.

We present a case report of a patient with a past medical history of polio, demonstrating our therapeutic approach not only upon initial presentation with acute-on-chronic respiratory failure, but also on the outpatient management of chronic respiratory failure.

\section{Case Report}

A 44-year-old man presented to the emergency department because of dyspnea and cough with purulent sputum in the previous week. He denied fever, chest pain and headache. The patient had a past medical history of polio when he was 4 years old with several motor sequelae namely skeletal deformities of thoracic cage including scoliosis and deformities of the four limbs, mobilizing only the upper left limb. He was moving in a wheelchair. The patient had undergone scoliosis surgery when he was 17 years old. He was a never smoker man who worked in the administrative services of a school despite his general functional limitation. Medical surveillance was made by orthopedist and family doctor.

On admission, the patient was awake and collaborating. He had polypnea and a peripheral oxygen saturation of $73 \%$. He was apyretic and hemodynamically stable. Cardiac and pulmonary auscultation were normal. Arterial blood gases analyze revealed respiratory acidemia and hypercapnic respiratory failure with signs of chronic hypoventilation $\left(\mathrm{FiO}_{2} 35 \%: \mathrm{pH}^{7.27}, \mathrm{pCO}_{2} 95\right.$ mmHg; $\mathrm{pO}_{2} 91, \mathrm{HCO}_{3} 43.6 \mathrm{mmol} / \mathrm{L}, \mathrm{satO}_{2} 96 \%$ ). The patient started treatment with noninvasive ventilation (NIV) with pressure support ventilation (PSV) - inspiratory positive airway pressure (IPAP) $17 \mathrm{cmH}_{2} \mathrm{O}$ and expiratory positive airway pressure (EPAP) $6 \mathrm{cmH}_{2} \mathrm{O}$ - and an oronasal interface. Adjuvant oxygen therapy was progressively reduced and the patient showed gasometric improvement with $\mathrm{pH}$ recovery to 7.35 and decrease of hypercapnia to $80 \mathrm{mmHg}$.

Blood analytical study showed hemoglobin $17.5 \mathrm{~g} / \mathrm{dL}$ without leukocytosis and C-reactive protein $0.65 \mathrm{mg} / \mathrm{dL}$. Chest X-ray (FIG. 1) revealed significant thoracic scoliosis and no consolidation suggestive of pneumonic focus. Diagnosis of acute-onchronic hypercapnic respiratory failure and tracheobronchitis were assumed and the patient was hospitalized in the pulmonology ward and started antimicrobial treatment.

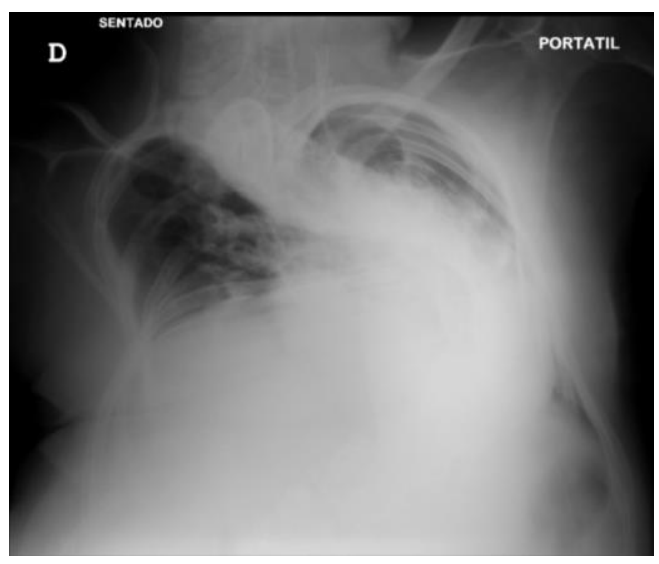

FIG. 1. Posteroanterior chest $x$-ray at emergency department admission. 
Two days later, he presented clinical worsening with new onset fever, depression of consciousness and gasometric worsening with NIV-refractory respiratory acidemia. He was transferred to the intensive care unit where he began invasive mechanical ventilation through an orotracheal tube and a new antibiotic treatment regimen. No microbiological etiology was defined. After prolonged ventilatory weaning and unsuccessful extubation attempts, the patient underwent tracheostomy and maintained ventilation through it. After clinical stability, the patient was again transferred to the pulmonology ward where he underwent progressive weaning from ventilation until he was able to receive treatment only at night. Decannulation with good healing evolution and tracheostomy closure were verified. At discharge, he was under nocturnal NIV with nasal interface (PS V mode, IPAP $16 \mathrm{cmH}_{2} 0$, EPAP $4 \mathrm{cmH}_{2} 0$, without adjuvant oxygen) with a good tolerance and presented a peripheral oxygen saturation in ambient air of $97 \%$ and the following blood gas analyzes - $\mathrm{pH} 7.41, \mathrm{pO}_{2} 72.0 \mathrm{mmHg}, \mathrm{pCO}_{2} 52.0 \mathrm{mmHg}, \mathrm{HCO}_{3}^{-} 33 \mathrm{mmol} / \mathrm{L}^{-}$ He was guided to maintain follow-up on NIV outpatient clinic.

More than seven years later, the patient is still on nocturnal NIV with nasal interface. He was not able to perform body plethysmography, but spirometry (FIG. 2) suggests a very severe restrictive ventilatory pattern with a forced vital capacity of $0.65 \mathrm{~L}$ ( $23 \%$ of predicted value). NIV has been delivered through PSV mode, with good tolerance and adhesion (use $>4$ hours: 98.9\% and mean daily use: 8-9 hrs). Air leaks have been controlled. Nocturnal pulse oximetry hasn`t revealed significant desaturation (mean oxygen saturation: $93 \%-94 \%$ and oxygen saturation <90\%: 4.9\%). However, more recently residual apneahypopnea index (AHI) has been slightly increased (8-9/h) and the patient developed mild hypercapnia under NIV (pH 7.40, $\left.\mathrm{pCO}_{2} 46.7 \mathrm{mmHg}, \mathrm{pO}_{2} 74.8 \mathrm{mmHg}, \mathrm{HCO}_{3}{ }^{-} 28.1 \mathrm{mmol} / \mathrm{L}\right)$. For that reason, IPAP has been increased to $18 \mathrm{cmH}_{2} 0$ and EPAP to $7 \mathrm{cmH} 20$. The patient has never again experienced any exacerbation or hospitalization and despite all his disabilities he stills working in the administrative services of a school.

$\begin{array}{lrrrr}\text { Parameter } & & \text { Pred } & \text { Test } & \text { oPred } \\ \text { SVC } & \text { L } & 2.90 & 0.66 & 22.8 \\ \text { FVC } & \mathrm{L} & 2.81 & 0.65 & 23.1 \\ \text { FEV 1 } & \mathrm{L} & 2.43 & 0.56 & 23.0 \\ \text { FEV 1/VC } & \text { \% } & 79.29 & 84.04 & 106.0 \\ \text { FEV 1/FVC } & \text { \% } & 86.32 & 85.72 & 99.3 \\ \text { FEV 6 } & \mathrm{L} & 3.08 & - & - \\ \text { PEF } & \mathrm{L} / \mathrm{M} & 425.98 & 205.62 & 48.3 \\ \text { FEF 25-75 } & \mathrm{L} / \mathrm{S} & 3.60 & 0.67 & 18.6 \\ \text { FEF2575/FVC \% } & 128.15 & 103.10 & 80.5 \\ \text { FEF 75-85 } & \mathrm{L} / \mathrm{S} & 0.91 & 0.16 & 17.2 \\ \text { FEF 25 } & \mathrm{L} / \mathrm{S} & 6.12 & 2.90 & 47.5 \\ \text { FEF 50 } & \mathrm{L} / \mathrm{S} & 3.74 & 1.04 & 27.9 \\ \text { FEF 75 } & \mathrm{L} / \mathrm{S} & 1.27 & 0.24 & 19.0 \\ \text { FIVC } & \mathrm{L} & 2.81 & 0.66 & 23.6 \\ \text { FIF 25 } & \mathrm{L} / \mathrm{S} & 2.90 & 1.40 & 48.2 \\ \text { FIF 50 } & \mathrm{L} / \mathrm{S} & 3.75 & 1.37 & 36.5 \\ \text { FIF 75 } & \mathrm{L} / \mathrm{S} & 2.05 & 1.15 & 56.4 \\ \text { MVV ind } & \mathrm{L} / \mathrm{M} & 90.97 & 20.89 & 23.0\end{array}$

FIG. 2. Spirometry suggesting a very severe restrictive ventilatory pattern.

\section{Discussion}

We have shown the role of NIV in the respiratory care of a polio survivor patient with several sequelae namely significant scoliosis and neuromuscular involvement. The clinical applicability of NIV lies both on acute and chronic hypercapnic respiratory failure. In addition, despite an initial clinical improvement in the acute setting with 
NIV, progressive clinical worsening was found requiring invasive ventilation through an orotracheal tube and later a trachostomy. This means that respiratory failure in these patients can be dynamic, requiring close surveillance and articulation with the intensive care unit. It is critical from the patient's admission to draw an anticipatory care plan that should involve the patient and family and decisions on escalation from noninvasive to invasive ventilation. Difficulties may also arise if the patient cannot be extubated back onto NIV because of extreme ventilator dependence or swallowing impairment in which case it is logical to perform a tracheostomy, an undesirable procedure. Decannulating and stepping down to NIV should be sought $[6,7]$.

Difficulties with cough and ineffective secretion clearance are another particular issue in patients with polio sequelae. It is therefore logical to apply combined use of NIV and cough assist strategies in the setting of both acute exacerbations and outpatient management of these patients [8,9].

After acute exacerbation, the patient presented criteria to domiciliary NIV which should be started when patients develop symptomatic nocturnal hypoventilation. Patients with daytime hypercapnia present inevitably worse gas exchange during sleep. NIV should be introduced before the development of daytime hypercapnia in order to reduce the risk of uncontrolled and unpredictable ventilation decompensation $[6,10]$.

Finally, we should be aware of a post-polio syndrome referring to a sub-category of the late effects of polio several years following the initial recovery, including muscle weakness and fatigability [11]. This late muscle involvement may also affect the respiratory muscles leading to chronic respiratory failure several years after primary infection $[12,13]$.

For all these reasons, polio continues to represent a current clinical condition in the field of Pulmonology not only because there are many survivors with established thoracic deformities and neuromuscular involvement, but also because of the possibility of late respiratory effects.

\section{Conflict of Interest}

The authors certify they have no affiliations or involvement with any organization or entity with any financial interest or nonfinancial interest in the subject matter or materials discussed in this manuscript.

\section{Sources of Funding}

None

\section{Consent}

Written informed consent was obtained from the patient for publication of this case report and accompanying images. 


\section{REFERENCES}

1. Kidd D, Williams AJ, Howard RS. Poliomyelitis. Postgr Med J. 1996;647(72):641-7.

2. Razum O, Sridhar D, Jahn A, et al. Polio: from eradication to systematic, sustained control. BMJ Glob Health. 2019;4(4):e001633.

3. Walley RV. Assessment of respiratory failure in poliomyelitis. Br Med J. 1959;2(5142):82-5.

4. West JB. The physiological challenges of the 1952 Copenhagen poliomyelitis epidemic and a renaissance in clinical respiratory physiology. J Appl Physiol. 2005;99(2):424-32.

5. Eichel T, Dreux ML. Negative or positive? The iron lung and poliomyelitis-Zurich, 1951. Anaesth Intensive Care. 2017;45(7):13-20.

6. Bach JR. Noninvasive respiratory management of patients with neuromuscular disease. Ann Rehabil Med. 2017;41(4):519-38.

7. McKim DA, Hendin A, Leblanc C, et al. Tracheostomy decannulation and cough peak flows in patients with neuromuscular weakness. Am J Phys Med Rehabil. 2012;91(8):666-70.

8. Boitano LJ. Management of airway clearance in neuromuscular disease. Respir Care. 2006;51(8):913-22.

9. Finder JD. Airway clearance modalities in neuromuscular disease. Paediatr Respir Rev. 2010;11(1):31-4.

10. Crimi C, Pierucci P, Carlucci A, et al. Long-Term Ventilation in Neuromuscular Patients: Review of Concerns, Beliefs, and Ethical Dilemmas. Respiration. 2019;97(3):185-96.

11. Chu ECP, Lam KKW. Post-poliomyelitis syndrome. Int Med Case Rep J. 2019;12:261-4.

12. Li Hi Shing S, Chipika RH, Finegan E, et al. Post-polio Syndrome: More Than Just a Lower Motor Neuron Disease. Front Neurol. 2019;10:773.

13. Shoseyov D, Cohen-Kaufman T, Schwartz I, et al. Comparison of activity and fatigue of the respiratory muscles and pulmonary characteristics between post-polio patients and controls: A pilot study. PLoS One. 2017;12(7):1-12. 